\title{
Emission quantification of refrigerant CFCs, HCFCs and HFCs in megacity Lahore (Pakistan) and contributed ODPs and GWPs
}

\author{
Zia Ul-Haq* D, Muhammad Ali, Syeda Adila Batool, Salman Tariq and Zarmina Qayyum \\ Remote Sensing and GIS Group, Department of Space Science, University of the Punjab, \\ New Campus, Lahore 54590, Pakistan. \\ *Corresponding author.e-mail: zia.spsc@yahoo.com
}

\begin{abstract}
An integrated assessment of emissions of some important refrigerant ozone depleting substances (ODSs) (CFC-11, CFC-12, HCFC-141b and HFC-134a) and their contributed ozone depletion potentials (ODPs) and global warming potentials (GWPs) have been made in the megacity Lahore (Pakistan) for the period from 2005 to 2013. During the production of 6.488 million refrigerator units, the cumulative estimated emissions of CFC-11, CFC-12, HCFC-141b and HFC-134a were 129.7, 6.8, 1257 and 104 mega grams (1 $\mathrm{Mg}=10^{6}$ grams). The estimated GWP $\left(\mathrm{CO}_{2}\right.$-eq) and ODP (CFC 11-eq) associated with production phase emissions of these four gases were 616.07, 73.52, 910.96, and 87.36 kilotonnes, and 129.7, 6.8, 139.4, and 0 tonnes, respectively. ODP of HFC-134a is considered to be zero. In addition, the repair and maintenance of 81.2 thousand units resulted in $10.8 \mathrm{Mg}$ emissions of CFC-12 with 10.8 tonnes ODP(CFC 11-eq) and 117,802 tonnes GWP ( $\mathrm{CO}_{2}$-eq) that were higher than the HFC-134a emissions recorded at $4.3 \mathrm{Mg}$ causing 4563 tonnes $\mathrm{GWP}\left(\mathrm{CO}_{2}\right.$-eq). A decrease in ODP (CFC 11-eq) and $\mathrm{GWP}\left(\mathrm{CO}_{2}\right.$-eq) at the rate of $-8.3 \%$ and $-8.2 \%$ per year is observed to be contributed by all the selected ODSs during the study period.
\end{abstract}

\section{Introduction}

Long lived halogenated gases which include chlorofluorocarbons (CFCs) and their alternatives such as hydrochlorofluorocarbons (HCFCs) and hydrofluorocarbons (HFCs) have wide-scale usage as refrigerants, solvents and aerosol propellants because of their excellent characteristics (James 2008; Rinsland et al. 2009). Their major role in stratospheric ozone depletion and global warming has been well documented (see, e.g., Brown et al. 2011 and references therein). The reactive elements Fluorine $(\mathrm{F})$, Chlorine $(\mathrm{Cl})$ and Bromine $(\mathrm{Br})$ are released from CFCs during solar ultraviolet photolysis in the stratosphere contributing to ozone depletion (WMO 2010). Also, CFCs and most of their alternatives strongly absorb infrared radiations making strong contributions to the anthropogenic greenhouse effect (IPCC 2007).

The Montreal Protocol (agreed on 16 September, 1987) has played a vital role in phasing out the production of CFCs and halons (UNEP 2009). Initially, CFCs have been replaced by HCFCs that have shorter atmospheric lifetimes because they quickly react with the hydroxyl radical, and have less ozone depletion potentials. However, HCFCs still destroy stratospheric ozone and they are in turn being phased out and replaced by HFCs (WMO 2010). Although HFCs do not have direct effects on stratospheric ozone, they are very strong

Keywords. Ozone depletion; global warming; refrigerant ODSs; Lahore. 
greenhouse gases (WMO 2010). HCFC-141b and HFC-134a are considered to be the substitutes for CFC-11 and CFC-12, respectively (Zhao 2011).

The alternative fluorocarbons environmental acceptability study (AFEAS 2009) that compiled global data for fluorocarbons revealed a decrease in the production of CFC-11 and CFC-12 gases from 232.9 to 2.04 kilotonnes (kt), and 230.95 to $8.94 \mathrm{kt}$, respectively, during 1990-2004. On the other hand, global productions had increased from 0.099 to $21.84 \mathrm{kt}$, and 0.189 to $158.161 \mathrm{kt}$ for HCFC-141b and HFC-134a, respectively, during the period 1990-2007. Liang et al. (2008) presented global spatial distribution of CFC-11 emissions. They clearly identified high emissions in the range of $0.20 \times 10^{-13} \mathrm{~kg} / \mathrm{m}^{2} / \mathrm{s}$ in Pakistan, India and Bangladesh. In Pakistan, high emission areas included the study region Lahore, megacities Karachi and Faisalabad. In India, the prominent emission areas were identified as Delhi, IndoGangetic Basin (IGB), and the eastern industrialised parts of India. The megacity Dhaka from
Bangladesh also appeared as a hotspot of CFC-11 emissions.

This study focuses on the emissions of four major halogenated refrigerant gases CFC-11 $\left(\mathrm{CCl}_{3} \mathrm{~F}\right)$, CFC-12 $\left(\mathrm{CCl}_{2} \mathrm{~F}_{2}\right)$, HCFC-141b $\left(\mathrm{CH}_{3} \mathrm{CCl}_{2} \mathrm{~F}\right)$, and HFC-134a $\left(\mathrm{CH}_{2} \mathrm{FCF}_{3}\right)$. Some of the basic characteristics, applications and lifetimes of these gases are given in table 1 . This study is intended to quantify the emissions of some important refrigerant CFCs and their substitutes, in order to address and evaluate their associated environmental impacts, including their contribution to ozone depletion and the greenhouse effect.

\section{Materials and methods}

\subsection{The study area and meteorology}

Lahore $\left(31.32^{\circ} \mathrm{N}, 74.22^{\circ} \mathrm{E}\right)$ is located in the most populous province of Punjab (Pakistan) with an area of $1172 \mathrm{~km}^{2}$. The population of Lahore is

Table 1. Applications, lifetimes, ODPs, and GWPs of selected ODSs (source: UNEP 2003; IPCC 2007; WMO 2011; SPARC 2013).

\begin{tabular}{|c|c|c|c|c|}
\hline ODSs & Major applications & $\begin{array}{l}\text { Lifetime } \\
\text { (years) }\end{array}$ & ODP & $\begin{array}{c}\text { GWP } \\
(100-y r)\end{array}$ \\
\hline CFC-11 & Refrigeration/freezing/foam blowing & 52 & 1 & 4750 \\
\hline CFC-12 & Refrigeration/freezing & 102 & 1 & 10,900 \\
\hline HCFC-141b & Foam blowing & 9.4 & 0.11 & 717 \\
\hline HFC-134a & $\begin{array}{l}\text { Refrigeration/freezing, air conditioning, } \\
\text { vehicle } \mathrm{A} / \mathrm{C} \text {, foam blowing }\end{array}$ & 14 & 0 & 1370 \\
\hline
\end{tabular}

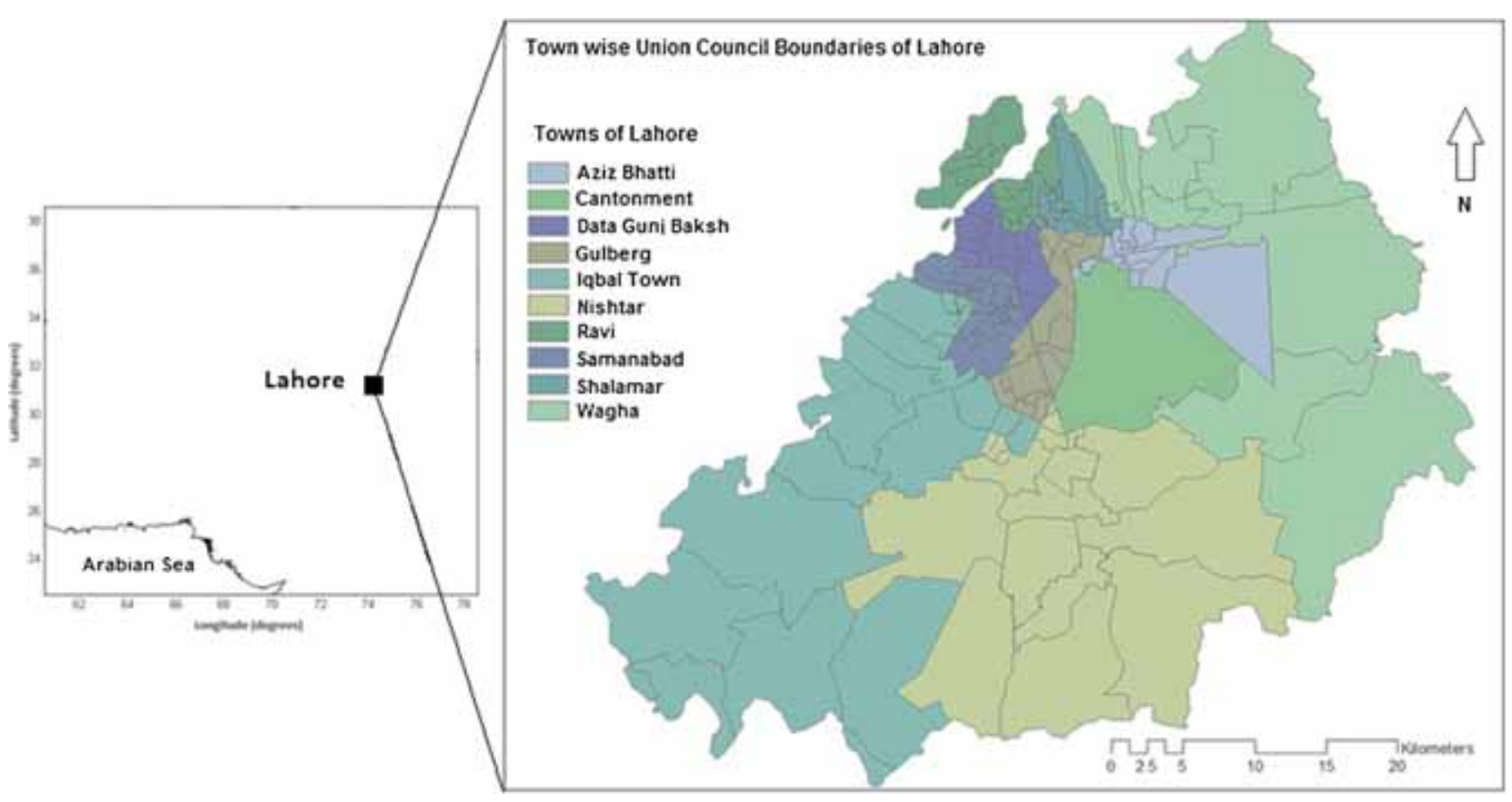

Figure 1. Geographical map showing the location of Lahore and boundaries of towns and union councils. 
10.05 million, based on the estimation in 2015 by Demographia World Urban Areas (DWUA 2015). Geographically, it is bounded by the Sheikhupura District, Wagah Border, and Kasur District. The northern side of Lahore is occupied by River Ravi. It is the 30th largest and 41st fastest growing city in the world (CMF 2015). Lahore consists of 151 union councils and 10 towns (figure 1). Industrial and manufacturing activities in Lahore include steel mills, pharmaceutical and chemical factories, construction materials, power generation, manufacturing of motor vehicles and refrigerators, and paper products (Alam et al. 2012; Ali et al. 2014). More than $80 \%$ of the industry of refrigerator and freezer (manufacturing and assembling) in Pakistan, is located in the study area.

The climate of Lahore is semi-arid with wet and very hot summers, and usually dry and cool winters. Heavy rainfall is observed in monsoon from late June to early September. Four dominant seasons can be defined on the basis of existing meteorological conditions in Lahore: winter (DJF), spring (MAM), summer (JJA), autumn (SON) (Ali et al. 2014). The major meteorological characteristics of Lahore have been summarised in figure 2.

\subsection{Estimation of $O D P$ and $G W P$}

Industry tours, field surveys and visits to the related sites (refrigerator factories, refrigerator repairing workshops and waste disposal sites) in Lahore have been made to quantify emissions of CFC-11, CFC-12, HCFC-141b and HFC-134a. The stratified random sampling (SRS) method was used in the collection of emission data. Based on different attributes and characteristics, 13 union councils from 5 towns have been selected as strata for random sampling. Data was acquired, regarding the number of units that were produced/ repaired/disposed-off, the number of workers in business and their qualifications, type and quantity of gas used, number of years in the business, and working/disposal methods. These estimated gaseous emissions were then translated into ozone depleting potentials (ODPs) and global warming potential (GWPs).

The ODP represents the global ozone loss associated with the release of a molecule, $i$, relative to the reference molecule (generally CFC-11) (Solomon et al. 1992). The ODP of a well-mixed ozonedestroying species, $i$, is given by the following simple expression (Daniel et al. 2007). where $i$ is the gas or the ozone depleting substance (ODS) in question. Studies have shown several reactions responsible for global ozone loss involving bromine, chlorine, iodine and fluorine freed from halogenated gases along with other atmospheric constituents such as carbon, oxygen, nitrogen, and hydrogen. Computer models backed by satellite observations are used to simulate these reactions and show that, under certain conditions, chlorine or bromine atoms react to destroy thousands of ozone molecules depending on their lifetimes (Fahey and Hegglin 2010). We have estimated ODP-weighted emissions, also known as CFC-11 equivalent emissions (ODP CFC 11-eq) expressed in tonnes. To obtain ODP (CFC 11-eq), the gas emission quantity is multiplied with its 100-year ODPs (WMO 2011).

GWPs are the indices used to quantify the cumulative radiative forcing of any trace gas, over a certain time horizon, relative to a reference gas such as $\mathrm{CO}_{2}$. The GWP of a gas is defined as (Harvey 2000)

$$
\operatorname{GWP}_{i}(T)=\frac{\int_{i}^{T} f_{i}(t) C_{i}(t) d t}{\int_{r}^{T} f_{r}(t) C_{r}(t) d t},
$$

where $f_{i}(t)$ and $f_{r}(t)$ are the heat-trapping abilities per unit mass, and $C_{i}(t)$ and $C_{r}(t)$ are the amounts remaining in the atmosphere at time $t$. The subscripts $i$ and $r$ refer to the gas in question (e.g., $\mathrm{ODS}$ ) and to the reference gas (e.g., $\mathrm{CO}_{2}$ ), respectively. $T$ is the time horizon, a 100 -year scale is adopted in this study, over which the integration is performed. GWP-weighted emissions, also known as $\mathrm{CO}_{2}$-equivalent emissions ( $\mathrm{GWP} \mathrm{CO}_{2}$-eq) are expressed in tonnes. To obtain GWP $\left(\mathrm{CO}_{2}\right.$-eq), gas emissions have been multiplied with its 100-year GWP (WMO 2011).

The following equations are used to calculate the annual release of refrigerant ODSs.

$$
R_{y+L}=P_{y} \times(1-\grave{\omega}) \times C \times r
$$

and

$$
R_{y+L}^{\prime}=P_{y} \times \grave{\omega} \times C \times r
$$

where $R$ is the annual release amount of remaining gas, $R^{\prime}$ is the annual release of substitute gas, $P_{y}$ is the annual production, $\grave{\omega}$ is the annual phase-out percentage of gas, $C$ is the average amount of therefrigerants and blowing agents used in each out-dated refrigerator ( $\mathrm{kg} / \mathrm{unit}), r$ is

$$
\mathrm{ODP}_{i}=\frac{\text { Global ozone loss due to unit mass emission of } i}{\text { Global ozone loss due to unit mass emission of CFC-11 }}
$$


the residual rate of refrigerants and foaming agents (\%), $L$ is the expected lifetime of refrigerator (average 15 years), and $y$ is the year of the computation (Ye and Tang 2001; Zhao 2011).

\section{Results and discussion}

Three phases have been considered for the emissions quantification of CFCs, HCFCs and HFCs, i.e., production, use/maintenance and waste/disposal phases.

\subsection{ODSs emissions during production phase}

The Pakistan market for refrigerators/freezers is mainly dominated by local assemblers and manufacturers. More than $80 \%$ of refrigerators/freezers assembling and manufacturing units of Pakistan are located in Lahore. Some of the major assemblers and manufacturers are Pak Elektron Limited (PEL), Dawlance, Cool Industries (Pvt), Orient, Candy and Hair. These have captured almost $90 \%$ of the total market share of Pakistan, and they also export their products to the Middle East,

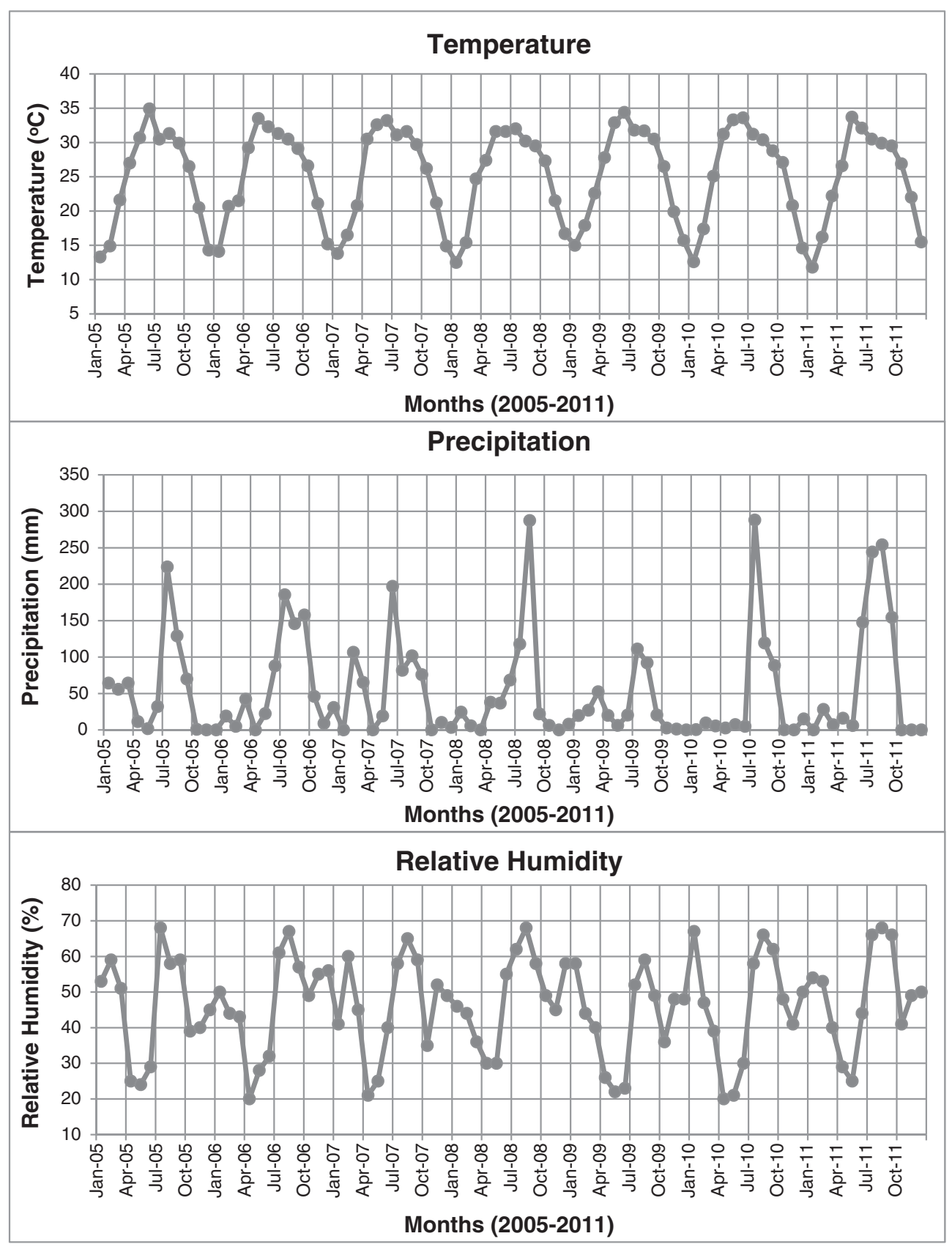

Figure 2. Mean monthly temperature $\left({ }^{\circ} \mathrm{C}\right)$, monthly amount of precipitation $(\mathrm{mm})$, mean monthly relative humidity at 1200 UTC (\%), mean monthly total cloud (all cloud) at 1200 UTC (Oktas), mean monthly atmospheric pressure (hPa) for Lahore during January 2005-December 2011 (Data source: Pakistan Meteorological Department, Karachi Centre, Pakistan). 


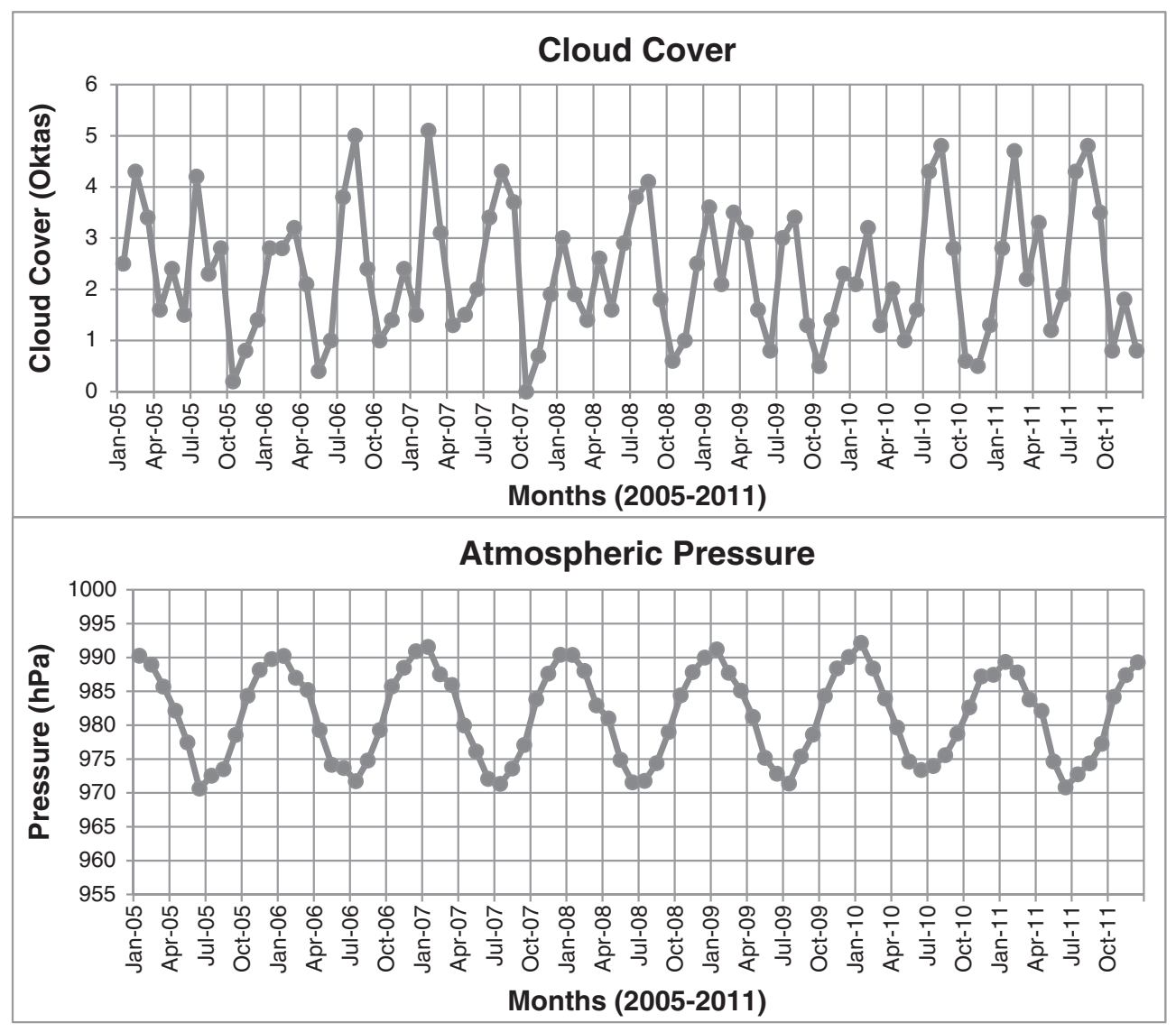

Figure 2. (Continued.)

Afghanistan, Bangladesh and some African countries as well (Pakistan Bureau of Statistics 2013). Pakistan is a signatory of Montreal Protocol for the protection of ozone layer and has successfully phased out CFCs emissions in production sector of refrigerators/freezers. The achieved phase-out percentages of CFCs are from $75 \%$ to $100 \%$ in the production sector during the period 2005-2011.

The amount of refrigerant and blowing agent used in polyurethane (PUR) insulation foams during assembling stage mainly depends on the size of the refrigerator. Large-sized refrigerators contain more amounts of coolant and blowing agent. The average amount of CFC-11 used for expanding foam is estimated to be $600 \mathrm{~g}$ per unit, and $40 \%$ of this amount is released into the atmosphere during the manufacturing phase (Dehoust and Schüler 2010). Therefore, about $240 \mathrm{~g}$ of CFC11 escape into the atmosphere and $360 \mathrm{~g}$ of CFC-11 remain present in PUR foam insulation. The annual estimated production of refrigerators using CFC-11 as blowing agent during the period 20052011 is given in table 2. This study finds a total amount of 129.699 megagrams (Mg) of CFC-11 emitted during the production process of 533,247 units for the period 2005-2011. The corresponding overall computed ODP (CFC 11-eq) and GWPs
$\left(\mathrm{CO}_{2}\right.$-eq) are 129.7 tonnes and $616.07 \mathrm{kt}$ respectively. ODP (CFC 11-eq) declining trend is seen at $-76 \%(-8.4 \%$ per year) (slope: $-4.5 \pm 0.9$, y-intercept: $\left.53.2 \pm 5.1, R^{2}=0.8\right)$ during the study period 2005-2013 (figure 3a). An overall decrease in GWP $\left(\mathrm{CO}_{2}\right.$-eq) from the selected ODSs has been observed to be $-64 \%$ ( $7.1 \%$ per year) (slope: $-20 \pm 4.6$, y-intercept: $291 \pm 26, R^{2}=0.7$ ) during the entire study period (figure $3 \mathrm{~b}$ ). The Montreal Protocol (1987) phase out programme has played a vital role in the reduction in the emissions of CFCs responsible for reducing ODP (CFC 11-eq) and GWP $\left(\mathrm{CO}_{2}\right.$-eq) during the production phase of refrigerators.

The average amount of CFC-12 refrigerant is estimated to be $250 \mathrm{~g}$ per averaged size unit, and $5 \%$ of this amount is released into the atmosphere during the production of a refrigerator (Dehoust and Schüler 2010). It means that, on average, $12.5 \mathrm{~g}$ of CFC-12 will be released into the atmosphere during the production of an average size refrigerator. Between 2005 and 2011, a total of $6.752 \mathrm{Mg}$ of CFC-12 has been released causing 7 tonnes ODP (CFC 11-eq) and 73,527 tonnes GWP $\left(\mathrm{CO}_{2}\right.$-eq) (table 2). The widely used CFC alternatives HCFC-141b has been found to emit $1257 \mathrm{Mg}$ with corresponding ODP (CFC 11-eq) 139 tonnes 
and GWP $\left(\mathrm{CO}_{2}\right.$-eq) $910.96 \mathrm{kt}$, whereas HFC-134a emissions are recorded at $64.2 \mathrm{Mg}$ resulting GWP $\left(\mathrm{CO}_{2}\right.$-eq) $87.36 \mathrm{kt}$ respectively during the complete study period.

It is observed that due to the released gases, the GWP $\left(\mathrm{CO}_{2}\right.$-eq) of CFC-11 and CFC-12 reached at their peaks of 186,860 and $22,302 \mathrm{Mg}$, respectively, in 2005, and then these were decreased gradually to zero until 2012 due to the phase-out program. The GWP ( $\mathrm{CO}_{2}$-eq) of their widely used alternatives HCFC-141b and HFC-134a were the lowest at 67,611 and 6506 tonnes, respectively, in 2005, and after that their amounts have increased almost linearly till 2013. Similarly, the ODP (CFC 11-eq) of CFC-11 and CFC-12 were found to have decreased significantly after 2005 while ODP weight of HCFC-141b increased significantly after 2005 .

Table 2. Statistics of CFC-11, CFC-12, HCFC-141b and HFC-134a emissions, and their corresponding ODPs (CFC 11-eq) and $G W P s\left(\mathrm{CO}_{2}-\mathrm{eq}\right)$ during the manufacturing phase in the study region for a period from 2005 to 2013. ODP of HFC-134a is zero.

\begin{tabular}{|c|c|c|c|c|}
\hline Year & $\begin{array}{l}\text { Units } \\
\text { (manufactured) }\end{array}$ & $\begin{array}{l}\text { Emissions } \\
\quad(\mathrm{kg})\end{array}$ & $\begin{array}{c}\text { ODP (CFC 11-eq) } \\
(\text { tonnes })\end{array}$ & $\begin{array}{c}\mathrm{GWP}\left(\mathrm{CO}_{2} \text {-eq }\right) \\
\text { (tonnes) }\end{array}$ \\
\hline \multicolumn{5}{|c|}{ CFC-11 } \\
\hline 2005 & 163916 & 39339 & 39.339 & 186860 \\
\hline 2006 & 105478 & 25314 & 25.314 & 120241 \\
\hline 2007 & 151614 & 36387 & 36.387 & 172838 \\
\hline 2008 & 35229 & 8454 & 8.454 & 40156 \\
\hline 2009 & 40000 & 9600 & 9.6 & 45600 \\
\hline 2010 & 37010 & 8882 & 8.882 & 42189 \\
\hline 2011 & 7180 & 1723 & 1.723 & 8184 \\
\hline 2012 & Phased-out & - & - & - \\
\hline 2013 & Phased-out & - & - & - \\
\hline \multicolumn{5}{|c|}{ CFC-12 } \\
\hline 2005 & 163916 & 2048 & 2.048 & 22302 \\
\hline 2006 & 105478 & 1318 & 1.318 & 14353 \\
\hline 2007 & 151614 & 1895 & 1.895 & 20636 \\
\hline 2008 & 35229 & 440 & 0.44 & 4791 \\
\hline 2009 & 40000 & 500 & 0.5 & 5445 \\
\hline 2010 & 37010 & 462 & 0.462 & 5031 \\
\hline 2011 & 7180 & 89 & 0.089 & 969 \\
\hline 2012 & Phased-out & - & - & - \\
\hline 2013 & Phased-out & - & - & - \\
\hline \multicolumn{5}{|c|}{ HCFC-141b } \\
\hline 2005 & 431748 & 93257 & 10.26 & 67611 \\
\hline 2006 & 537711 & 116145 & 12.78 & 84205 \\
\hline 2007 & 606458 & 130994 & 14.41 & 94970 \\
\hline 2008 & 659368 & 142423 & 16.72 & 103256 \\
\hline 2009 & 750007 & 152001 & 16.71 & 110200 \\
\hline 2010 & 703194 & 151889 & 16.89 & 110119 \\
\hline 2011 & 703194 & 153558 & 16.89 & 111329 \\
\hline 2012 & 774165 & 157219 & 17.29 & 113983 \\
\hline 2013 & 782510 & 159022 & 17.49 & 115290 \\
\hline \multicolumn{5}{|c|}{ HFC-134a } \\
\hline 2005 & 431748 & 4749 & & 6506 \\
\hline 2006 & 537711 & 5314 & & 7280 \\
\hline 2007 & 606458 & 6571 & & 9002 \\
\hline 2008 & 659368 & 7253 & & 9336 \\
\hline 2009 & 750007 & 8250 & & 11302 \\
\hline 2010 & 703194 & 7735 & & 10596 \\
\hline 2011 & 703194 & 7320 & & 10028 \\
\hline 2012 & 774165 & 8515 & & 11665 \\
\hline 2013 & 782510 & 8507 & & 11654 \\
\hline
\end{tabular}




\subsection{ODSs emissions during use/maintenance phase}

ODSs emissions during use/maintenance phase mainly depend on the amount used in a given application, the design and efficiency of the equipment, the overall cooling and refrigeration requirements, the maintenance of the equipment, the method of servicing and the leakage during the use (Harvey 2000). On average household refrigerator units contain around 145-240 g of a coolant. During the life and operational period, gas leakage may be observed due to (a) seepage through the holes and gaps developed due to mechanical damage or defects which can be seen in the equipment, (b) leakage during the movement/relocation of the equipment, (c) leakage through holes produced during wiping of ice with sharp tools in directcool refrigerators, (d) release during refilling by untrained/unqualified workers, and (e) release of small quantity of gas left over in each gas container.

The industry in Pakistan only manufactures 'direct cool' refrigerators; 'no frost' refrigerators are not manufactured. During the maintenance workshops survey, it is found that the electric power load shedding with short cycle power tripping and severe voltage fluctuations are the primary causes of refrigerator compressor failures
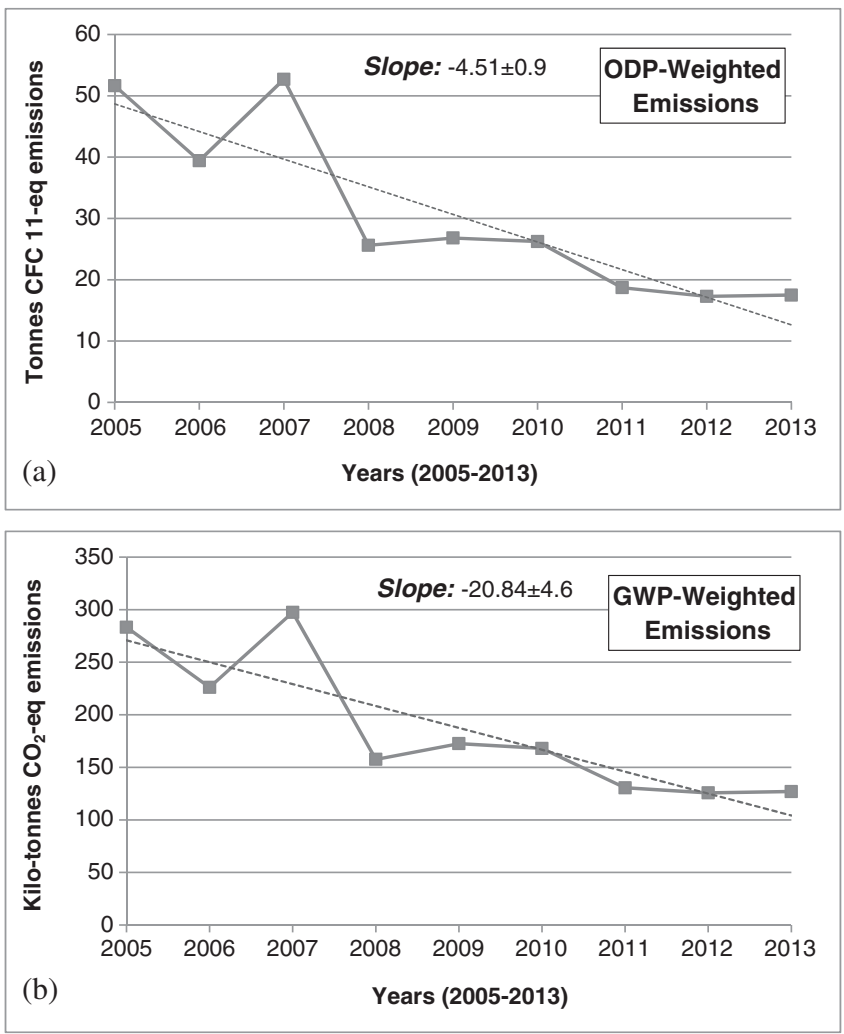

Figure 3. (a) ODP weighted emissions (CFC 11-eq) and (b) GWP weighted emissions $\left(\mathrm{CO}_{2}\right.$-eq) during production phase for a period from 2005 to 2013 in Lahore. which are significantly responsible for the gas release. In addition, more than $70 \%$ of technicians are unqualified and unaware of good practices of refilling and proper repairing of the equipment. During the repair and maintenance of 81.2 thousand units, the emissions of refrigerant CFC-12 were $10.8 \mathrm{Mg}$ with corresponding 10.8 tonnes ODP (CFC 11-eq) and 117,802 tonnes GWP $\left(\mathrm{CO}_{2}\right.$-eq) that were higher than the $4.3 \mathrm{Mg}$ emissions of HFC-134a causing 4563 tonnes GWP $\left(\mathrm{CO}_{2}\right.$-eq) (table 3).

During the use/maintenance phase, an overall decrease of $-18 \%$ ( $-2 \%$ per year) (slope: $-0.03 \pm$ $0.01, y$-intercept: $\left.1.33 \pm 0.03, R^{2}=0.79\right)$ in ODP (CFC 11-eq) contributed from the selected ODSs have been observed during the study period, 20052013 (figure 4a). A similar trend is also observed for GWP $\left(\mathrm{CO}_{2}\right.$-eq). A reduction in $\mathrm{GWP}\left(\mathrm{CO}_{2}\right.$-eq $)$ from the ODSs is noted at $-16 \%(-1.7 \%$ per year $)$ (slope: $-0.26 \pm 0.06$, y-intercept: $14.89 \pm 0.32$, $R^{2}=0.74$ ) during the study period (figure $4 \mathrm{~b}$ ). The decreases in ODP (CFC 11-eq) and GWP $\left(\mathrm{CO}_{2}\right.$-eq) are mainly attributed to the decline in $\mathrm{CFC}-11$ and CFC-12 emissions during this phase.

It is also observed that the banned CFC-12 is still being refilled as a refrigerant, in about $9 \%$ of the old refrigerators in the study area during the operational phase. It has been reported that Pakistan receives a considerable quantity of smuggled CFCs through its land borders (EIAR 2001). The main reasons for continued CFCs usage are low-cost of ODSs, the high cost of ODSs substitutes, expensive retrofitting of the equipment to enable use of alternative chemicals, longer lifetime of CFC-containing equipment, paltry penalties regarding ODSs smuggling, and traditional mindset of unqualified technicians (EIAR 2001; The State of Environment in Asia 2006).

\subsection{ODSs emissions during waste/disposal phase}

The amount of blowing agent contained in PUR foam before disposal is estimated to be $360 \mathrm{~g}$ on average. Thus, the loss of blowing agent to air during manual foam stripping of carcasses (cabinet plus door) has been estimated to $108 \mathrm{~g}$ (30\%) of the original content of the foam and gas held in the foam residues is estimated to be $36 \mathrm{~g}$ (10\%) with respect to the original amount of blowing agent (Dehoust and Schüler 2010). This means that estimated total loss of CFC-11 and HCFC$141 \mathrm{~b}$ was $40 \%$ of original amount per carcass with an average value of $144 \mathrm{~g}$, while an estimated $100 \%$ loss of CFC-12 and HFC-134a during manual disposal has been observed. During the disposal of 24,436 units, the estimated total emissions of CFC11, CFC-12, HCFC-141b and HFC-134a were 4.1, 
Table 3. Statistics of CFC-12 and HFC-134a emissions, and their corresponding ODPs (CFC 11-eq) and $G W P s\left(\mathrm{CO}_{2}-e q\right)$ during the operational life and maintenance phase in the study region for a period from 2005 to 2013. ODP of HFC-134a is zero.

\begin{tabular}{lcccc}
\hline Year & $\begin{array}{c}\text { Units } \\
(\text { Repaired })\end{array}$ & $\begin{array}{c}\text { Emissions } \\
(\mathrm{kg})\end{array}$ & $\begin{array}{c}\text { ODP (CFC 11-eq) } \\
\text { (tonnes) }\end{array}$ & $\begin{array}{r}\text { GWP (CO } \text {-eq) } \\
\text { (tonnes) }\end{array}$ \\
\hline CFC-12 & & & & \\
2005 & 7231 & 1373 & 1.373 & 14951 \\
2006 & 6369 & 1210 & 1.21 & 13176 \\
2007 & 6580 & 1250 & 1.25 & 13612 \\
2008 & 6567 & 1247 & 1.247 & 13579 \\
2009 & 6205 & 1178 & 1.178 & 12828 \\
2010 & 6138 & 1166 & 1.166 & 12697 \\
2011 & 6049 & 1149 & 1.149 & 12512 \\
2012 & 5970 & 1134 & 1.139 & 12403 \\
2013 & 5824 & 1106 & 1.106 & 12044 \\
HFC-134a & & & & 348 \\
2005 & 3037 & 619 & & 527 \\
2006 & 2950 & 604 & & 565 \\
2007 & 2844 & 486 & & 576 \\
2008 & 2890 & 494 & & 535 \\
2009 & 2715 & 464 & & 584 \\
2010 & 2667 & 456 & & 583 \\
2011 & 2510 & 429 & & \\
2012 & 2407 & 411 & & \\
2013 & 2300 & 393 & & \\
\hline
\end{tabular}
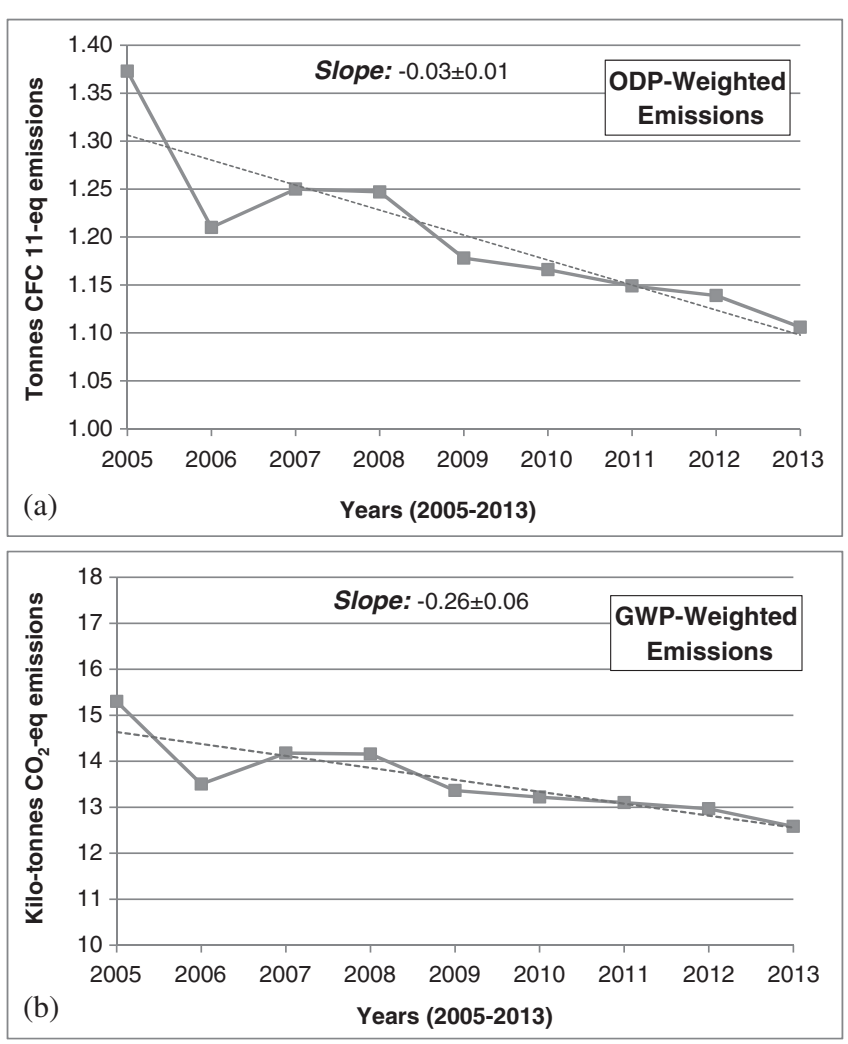

Figure 4. (a) ODP weighted emissions (CFC 11-eq) and (b) GWP weighted emissions $\left(\mathrm{CO}_{2}\right.$-eq) during use/maintenance phase for a period from 2005 to 2013 in Lahore.
9.2, 1.5 and $2.5 \mathrm{Mg}$. The ODP (CFC 11-eq) and GWPs $\left(\mathrm{CO}_{2}\right.$-eq) associated with these emissions are given in table 4 . A decrease in ODP (CFC 11eq) contributed by the selected ODSs is seen at $-75 \%$ ( $-8.3 \%$ per year) (slope: $-0.1 \pm 0.01, \mathrm{y}-$ intercept: $\left.1.25 \pm 0.07, R^{2}=0.9\right)$ during the study period 2005-2013 (figure 5a). Also, the reduction in GWP $\left(\mathrm{CO}_{2}\right.$-eq) is found to be $-74.2 \%(-8.2 \%$ per year) (slope: $-0.88 \pm 0.13$, y-intercept: $10.66 \pm$ $0.76, R^{2}=0.86$ ) during the study period of $2005-$ 2013 (figure 5b). The main causes of the decline in the ODP (CFC 11-eq) and GWP $\left(\mathrm{CO}_{2}\right.$-eq) during this phase are associated with the reduced emissions due to phase out process.

The period between 2005 and 2013 is a critical time during which the CFCs and their replacements from refrigerators/freezers in Lahore contributed significantly to ozone depletion and the greenhouse effect. In addition, the lifetimes of CFC-11, CFC-12, HCFC-141b and HFC-134a are $52,102,9.4$ and 14 years, respectively. Thus, the CFC-11 and HCFC-141b will actively play their role in environmental degradation until 2050-2063 and 2014-2022 approx., respectively, while CFC-12 and HFC-134a will also remain in the atmosphere till 2105-2115 and 2019-2027 approx., respectively. These will be actively contributing to ozone depletion and the greenhouse effect.

The European Union regulation (No. 1005/2009), on substances that deplete the ozone layer, includes 
provisions on the environmentally and climatically compatible retrievals of ODSs from products and their subsequent ultimate destruction. This regulation sets recovery and recycling of ODSs from discarded equipment. There are no mechanisms developed and treatment plant facilities are available in Pakistan to recover and recycle ODSs from the discarded products containing CFCs and their substitutes. During the study, not a single practice was found established to recover ODSs from the equipment being discarded and containers with a small amount of leftover gas. ODSs-blown foams are disposed of in open landfill sites leading to the release of very significant quantities of ODSs into the atmosphere.

Our emission trends of selected gases/ODSs are in close association with the WMO (2010) global emission trends, and ground-based measurements of tropospheric mixing ratios.

The Scientific Assessment of Ozone Depletion 2010 (WMO 2010) presented the global ODP and GWP-weighted emissions of ODSs and their

Table 4. Statistics CFC-11, CFC-12, HCFC-141b and HFC-134a emissions, and their corresponding ODPs (CFC 11-eq) and GWPs (CO $\left.\mathrm{CO}_{2}-\mathrm{eq}\right)$ during the waste/disposal phase in the study region for a period from 2005 to 2013. ODP of HFC-134a is zero.

\begin{tabular}{|c|c|c|c|c|}
\hline Years & $\begin{array}{c}\text { Units } \\
\text { (wasted) }\end{array}$ & $\begin{array}{l}\text { Emissions } \\
\qquad(\mathrm{kg})\end{array}$ & $\begin{array}{c}\text { ODP (CFC 11-eq) } \\
\text { (tonnes) }\end{array}$ & $\begin{array}{c}\mathrm{GWP}\left(\mathrm{CO}_{2}-\mathrm{eq}\right) \\
(\text { tonnes })\end{array}$ \\
\hline \multicolumn{5}{|c|}{ CFC-11 } \\
\hline 2005 & 2917 & 420 & 0.42 & 1395 \\
\hline 2006 & 2610 & 375 & 0.375 & 1781 \\
\hline 2007 & 2467 & 355 & 0.355 & 1586 \\
\hline 2008 & 2290 & 329 & 0.329 & 1562 \\
\hline 2009 & 2159 & 310 & 0.31 & 1472 \\
\hline 2010 & 2070 & 298 & 0.298 & 1415 \\
\hline 2011 & 1310 & 188 & 0.188 & 393 \\
\hline 2012 & 950 & 136 & 0.136 & 546 \\
\hline 2013 & 517 & 74 & 0.074 & 351 \\
\hline \multicolumn{5}{|c|}{ CFC-12 } \\
\hline 2005 & 2917 & 694 & 0.594 & 6462 \\
\hline 2006 & 2610 & 621 & 0.621 & 6762 \\
\hline 2007 & 2467 & 587 & 0.587 & 6392 \\
\hline 2008 & 2290 & 545 & 0.545 & 5335 \\
\hline 2009 & 2159 & 513 & 0.513 & 5586 \\
\hline 2010 & 2070 & 492 & 0.492 & 5357 \\
\hline 2011 & 1310 & 311 & 0.311 & 3386 \\
\hline 2012 & 950 & 226 & 0.226 & 2461 \\
\hline 2013 & 517 & 123 & 0.123 & 1339 \\
\hline \multicolumn{5}{|c|}{ HCFC-141b } \\
\hline 2005 & 1255 & 161 & 0.017 & 116 \\
\hline 2006 & 1150 & 148 & 0.016 & 107 \\
\hline 2007 & 1090 & 140 & 0.015 & 101 \\
\hline 2008 & 1003 & 129 & 0.014 & 93 \\
\hline 2009 & 867 & 111 & 0.012 & 80 \\
\hline 2010 & 650 & 83 & 0.009 & 60 \\
\hline 2011 & 490 & 63 & 0.006 & 45 \\
\hline 2012 & 342 & 44 & 0.004 & 31 \\
\hline 2013 & 299 & 38 & 0.004 & 27 \\
\hline \multicolumn{5}{|c|}{ HFC-134a } \\
\hline 2005 & 1255 & 268 & & 367 \\
\hline 2006 & 1150 & 246 & & 337 \\
\hline 2007 & 1090 & 233 & & 319 \\
\hline 2008 & 1003 & 214 & & 293 \\
\hline 2009 & 867 & 185 & & 253 \\
\hline 2010 & 650 & 139 & & 190 \\
\hline 2011 & 490 & 104 & & 142 \\
\hline 2012 & 342 & 73 & & 100 \\
\hline 2013 & 299 & 63 & & 86 \\
\hline
\end{tabular}


substitutes from the period 1950-2050. The sharp and gradual decrease in CFCs is noted. The accelerated phase down in HCFC emissions is observed and the expected reduction in cumulative HCFC emissions is about 0.7 million ODP (CFC 11-eq) tonnes during 2011 and 2050. It is also predicted that HCFC associated GWP ( $\mathrm{CO}_{2}$-eq) emissions will decrease by about 0.5 gigatonnes per year averaged for 2011-2050. On the other hand, a phenomenal growth was seen in HFC's emissions.
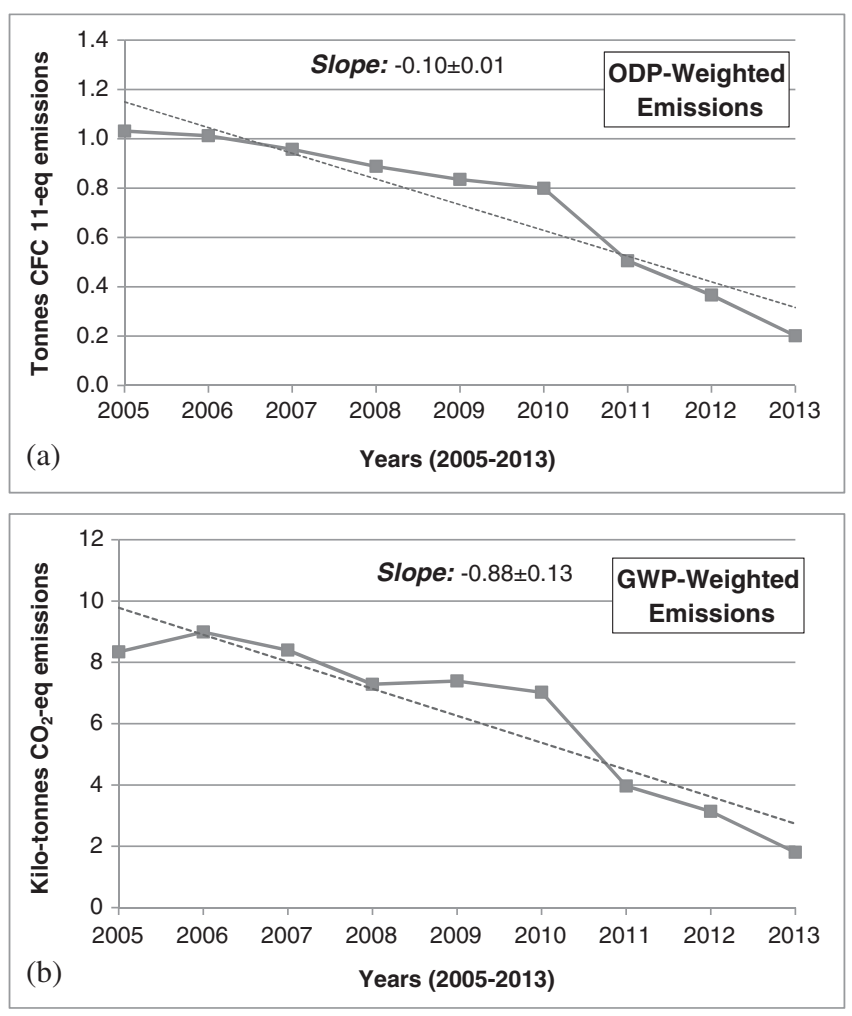

Figure 5. (a) ODP weighted emissions (CFC 11-eq), and (b) GWP weighted emissions $\left(\mathrm{CO}_{2}\right.$-eq) during waste/disposal phase for a period from 2005 to 2013 in Lahore.
The projected growth in HFCs, that assumes no controls, suggests that by 2050 the GWP weighted emissions from these substances could be comparable to the GWP weighted emissions of CFCs at their peak in 1988 (WMO 2010).

The ground-based measurements provide an indication of the tropospheric loading and tendency of individual ODS emissions. Recent changes in tropospheric mixing ratios of $\mathrm{CFC}-11, \mathrm{CFC}-12$, HCFC-141b and HFC-134a have been measured from samples collected at ground-based sites at different locations globally (Montzka et al. 1999, 2003; NOAA 2015). The time series based on annual mean data obtained from National Oceanic and Atmospheric Administration-Global Monitoring Division (NOAA 2015) indicated declining trends of global tropospheric mixing ratios of CFC-11 and CFC-12, whereas the tropospheric burdens of HCFC-141b and HFC-134a were observed to be on the rise (figure 6).

CFC-11 tropospheric concentration peaked with a value of 271.14 ppt in 1994 and afterwards, it showed a decreasing trend. The global CFC-11 concentration during the study period (2005-2013) decreased from 251.7 to 234.7 ppt showing an overall reduction of $-7.6 \%(-2.14$ ppt per year). The CFC-12 concentration showed the highest concentration of 543.11 ppt in 2002. It decreased from 545.06 to $522.43 \mathrm{ppt}(-4.15 \%)$ during the period of 2005-2013 with an yearly drop of $2.52 \mathrm{ppt}$. The declining global trend of CFC-11 and CFC-12 are observed to be less dramatic because of continuing emissions and their long lifetimes (50-100 years). The replacement HCFC-141b gradually elevated in the troposphere during the study period (20052013 ) with $37.5 \%$ increase (0.69 ppt per year), from 16.62 to $22.86 \mathrm{ppt}$. The mixing ratios of HCFCs have continued to increase and their production is not scheduled for a complete phase-out until 2030. An accelerated growth was observed in the

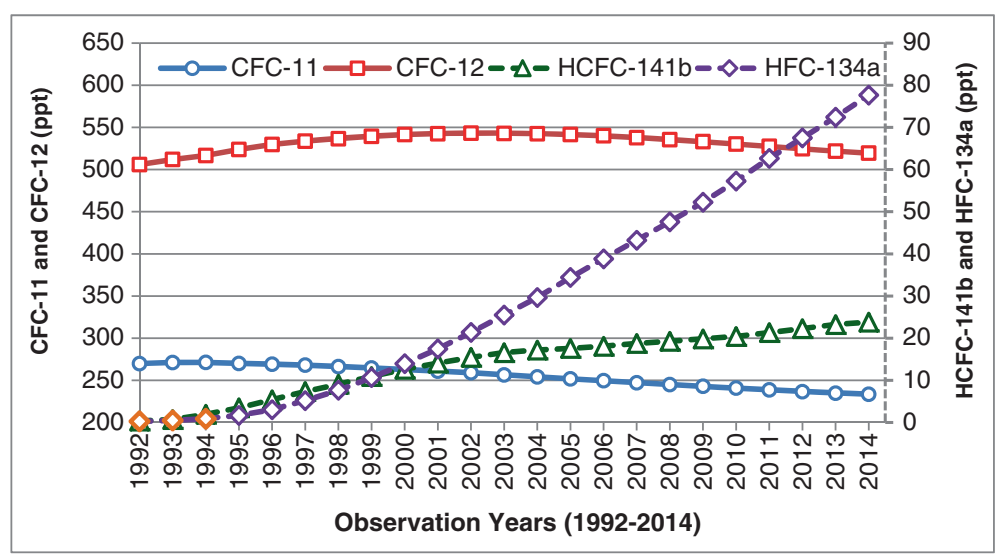

Figure 6. Global tropospheric mixing ratio estimates, weighted averages of measured mixing ratios, of ozone depleting substances (ODSs) (in ppt) during 1992-2014. Orange line markers represent HFC-134a extrapolated back in time values for 1992-1994. Dotted lines belong to secondary vertical axis (Data source: NOAA's Global Monitoring Division (NOAA 2015)). 
burden of HFC-134a during 2005-2013 with an overall increase of $148.16 \%$, ranging from 29.02 to $72.02 \mathrm{ppt}$.

These results imply that the large amounts of CFCs and their substitutes released from during production, and from in-use and discarded refrigerators in Lahore will continue making a significant contribution to the global budget of atmospheric CFCs and their alternatives. Consequentially, the released refrigerants will also lead to ozone depletion and global warming for several coming years.

In this study, we have used globally averaged ODPs and GWPs for the selected ODSs. Solomon et al. (1992) highlighted the importance of local ODP as it varies with latitude, seasons and altitude. They developed a semi-empirical approach to get local ozone depletion potential. A comparison with the values of Solomon et al. (1992) and other models requires a detailed treatment and is recommended for future work.

\section{Conclusion}

An assessment of emissions of some important refrigerant ODSs (CFC-11, CFC-12, HCFC-141b and HFC-134a) has been made in megacity Lahore (Pakistan) for a period from 2005 to 2013. During the three phases of production, usage and disposal of refrigerators, the total quantified emission of these gases was $1418.7 \mathrm{Mg}$ during the study period in Lahore. These emissions are responsible for 293.303 tonnes of ODP (CFC 11-eq) and 1.867 Megatonnes of GW ( $\mathrm{CO}_{2}$-eq). The banned CFC-12 is still found to be refilled as a refrigerant in Lahore. During the production of 6.488 million refrigerator units, the cumulative estimated emissions of CFC-11, CFC-12, HCFC-141b and HFC-134a were found to be 129.7, 6.8, 1257 and $104 \mathrm{Mg}$. The estimated GWP $\left(\mathrm{CO}_{2}\right.$-eq) and ODP (CFC 11-eq) associated with production phase emissions of these four gases were $616.07,73.52,910.96$, and $87.36 \mathrm{kt}$, and $129.7,6.8,139.4$, and 0 tonnes, respectively. In addition, the repair and maintenance phase contributed to $10.8 \mathrm{Mg}$ emissions of CFC-12 with 10.8 tonnes $\mathrm{ODP}(\mathrm{CFC} 11$-eq) and 117,802 tonnes GWP $\left(\mathrm{CO}_{2}\right.$-eq) that were higher than the HFC$134 \mathrm{a}$ emissions recorded at $4.3 \mathrm{Mg}$ causing 4563 tonnes $\mathrm{GWP}\left(\mathrm{CO}_{2}\right.$-eq). Also, an yearly decrease of $-8.3 \%$ and $-8.2 \%$ in ODP (CFC 11-eq) and GWP $\left(\mathrm{CO}_{2}\right.$-eq) is estimated, contributed by all the selected ODSs during the study period. The presented trends of ODSs are in agreement with global trends discussed using tropospheric gases/ODSs mixing ratios data obtained from National Oceanic and Atmospheric Administration-Global Monitoring Division (NOAA-GMD).

\section{Acknowledgements}

We thank the editor and the anonymous reviewers for their constructive comments, which helped us improve the original manuscript greatly. The authors acknowledge the Pakistan Meteorological Department, Karachi centre for the meteorological data. We also thank the National Oceanic and Atmospheric Administration-Global Monitoring Division (NOAA-GMD) for tropospheric gases/ODSs mixing ratios.

\section{References}

AFEAS (Alternative Fluorocarbons Environmental Acceptability Study) 2009 Production, sales and atmospheric release of fluorocarbons through 2006; FEAS Program Office, Arlington, VA, USA, www.afeas.org/data.php.

Alam K, Trautmann T, Blaschke T and Majid H 2012 Aerosol optical and radiative properties during summer and winter seasons over Lahore and Karachi; Atmos. Environ. $50234-245$.

Ali M, Tariq S, Mahmood K, Daud A, Batool A and ul-Haq Z 2014 A study of aerosol properties over Lahore (Pakistan) by using AERONET data; Asia Pac. J. Atmos. Sci. 50 153-162.

Brown A T, Chipperfield M P, Boone C, Wilson C, Walker K A and Bernath P F 2011 Trends in atmospheric halogen containing gases since 2004; J. Quant. Spectrosc. Radiat. Transfer 112 2552-2566.

CMF 2015 City Mayors Foundation UK, www.citymayors. com.

Daniel J S, Velders G J M, Douglass A R, Forster P M D, Hauglustaine D A, Isaksen I S A, Kuijpers L J M, McCulloch A, Wallington T J, Ashford P, Montzka S A, Newman P A and Waugh D W 2007 Halocarbon scenarios, ozone depletion potentials, and global warming potentials; In: Scientific Assessment of Ozone Depletion: 2006, Global Ozone Res. Monit. Proj. Rep. 50, World Meteorol. Org., Geneva, Switzerland, pp. 8.1-8.39.

Dehoust G and Schüler D 2010 Study of the ozone depletion and global warming potentials associated with fridge recycling operations that involve the manual stripping of polyurethane insulation foam; Öko-Institut e.V Darmstadt, Germany, http://www.oeko.de/oekodoc/ 1100/2009-130-en.pdf.

DWUA 2015 Demographia World Urban Areas; 11th annual edn 2015.01 (Built Up Urban Areas or World Agglomerations), http://www.demographia.com/ db-worldua.pdf.

EIAR (Environmental Investigation Agency Report) 2001 Unfinished Business: The Continued Illegal Trade in Ozone Depleting Substances and the Threat Posed to the Montreal Protocol Phase out; London.

Fahey D W and Hegglin M I (Coordinating Lead Authors) 2010 Twenty questions and answers about the ozone layer: 2010 Update, Scientific Assessment of Ozone Depletion: 2010, 72p, World Meteorological Organization, Geneva, Switzerland 2011. [Reprinted from Scientific Assessment of Ozone Depletion: 2010, Global Ozone Research and Monitoring Project-Report No. 52, 516p, World Meteorological Organization, Geneva, Switzerland 2011.] 
Harvey L D D 2000 Global Warming: The Hard Science; Prentice-Hall, Harlow, UK, 336p, ISBN 0582-38167-3.

IPCC: Climate Change 2007 The Physical Science Basis; Contributions of Working Group I to the Fourth Assessment Report of the Intergovernmental Panel on Climate Change; Cambridge University Press.

James M C 2008 The next generation of refrigerants - historical review, considerations, and outlook; Int. J. Refrig. 31(7) 1123-1133.

Liang Q, Stolarski R S, Douglass A R, Newman P A and Nielsen J E 2008 Evaluation of emissions and transport of CFCs using surface observations and their seasonal cycles and the GEOS CCM simulation with emissions-based forcing; J. Geophys. Res. 113 D14302, doi: 10.1029/2007JD009617.

Montzka S A, Butler J H, Elkins J W, Thompson T M, Clarke A D and Lock L T 1999 Present and future trends in the atmospheric burden of ozone-depleting halogens; Nature 398(6729) 690-694.

Montzka S A, Butler J H, Hall B D, Mondeel D J and Elkins $\mathrm{J}$ W 2003 A decline in tropospheric organic bromine; Geophys. Res. Lett. 30(15) 1826.

NOAA (National Oceanic and Atmospheric Administration) 2015 Online repository of global tropospheric mixing ratios of ozone-depleting gases; ftp://ftp.cmdl.noaa. gov/hats/Total_Cl_Br/.

Pakistan Bureau of Statistics 2013 www.pbs.gov.pk.

Rinsland C P, Chiou L, Boone C, Bernath P and Mahieu E 2009 First measurements of the HCFC-142b trend from atmospheric chemistry experiment (ACE) solar occultation spectra; J. Quant. Spectrosc. Radiat. Transfer 110 $2127-2134$
Solomon S, Mills M, Heidt L E, Pollock W H and Tuck A F 1992 On the evaluation of ozone depletion potentials; J. Geophys. Res. Atmos. 97(D1) 825-842.

SPARC 2013 SPARC Report on the Lifetimes of Stratospheric Ozone-Depleting Substances, their Replacements, and Related Species (eds) Ko M K W, Newman P A, Reimann S and Strahan S E, SPARC Report No. 6, WCRP-15/2013, www.sparc-climate.org/publications/ sparc-reports/.

The State of Environment in Asia: 2005/ 2006, 3rd edn (ed.) Takehisa Awaji, Japan Environmental Council (JEC) and Shun'ichi Teranishi; Springer Science \& Business Media, Japan.

UNEP (United Nation Environment Program) 2003 Handbook for International Treaties for Protection of the Ozone Layers; 6th edn, Nairobi, Kenya.

UNEP (United Nations Environmental Program) 2009 Handbook for the Montreal Protocol on Substances that Deplete the Ozone Layer; 6th edn, Nairobi, Kenya.

WMO (World Meteorological Organization) 2010 Scientific Assessment of Ozone Depletion: 2010; Global Ozone Research and Monitoring Project-Report No. 52, Geneva.

WMO (World Meteorological Organization) 2011 Scientific Assessment of Ozone Depletion: 2010; Global Ozone Research and Monitoring Project-Report No. 52, 516p, Geneva.

Ye L S and Tang X H 2001 Comparison of the greenhouse effects between CFCs and alternatives for CFCs from household refrigerators; Environ. Sci. Technol. 25(4) 17-20.

Zhao X 2011 An evaluation on the environmental consequences of residual CFCs from obsolete household refrigerators in China; Waste Manag. 31 555-560. 